\title{
Nowak et al. reply
}

\section{Citation}

Nowak, Martin A., Corina E. Tarnita, and Edward O. Wilson. 2011. "Nowak et Al. Reply." Nature 471 (7339) (March 24): E9-E10. doi:10.1038/nature09836.

\section{Published Version}

doi:10.1038/nature09836

\section{Permanent link}

http://nrs.harvard.edu/urn-3:HUL.InstRepos:22565795

\section{Terms of Use}

This article was downloaded from Harvard University's DASH repository, and is made available under the terms and conditions applicable to Open Access Policy Articles, as set forth at http:// nrs.harvard.edu/urn-3:HUL.InstRepos:dash.current.terms-of-use\#OAP

\section{Share Your Story}

The Harvard community has made this article openly available.

Please share how this access benefits you. Submit a story.

Accessibility 


\section{Nowak et al. reply}

Our paper challenges the dominant role of inclusive fitness theory (IFT) in the study of social evolution ${ }^{1}$. We show that IFT is not a constructive theory that would allow a useful mathematical analysis of evolutionary processes. For studying evolution of cooperation or eusociality we must instead rely on evolutionary game theory or population genetics. The authors of the five letters offer the usual defense of IFT, but do not take into account our new results.

The concept of inclusive fitness assumes that the fitness of individuals can be split into additive components caused by individual actions ${ }^{2}$ (Box 1$)$. This approach rests on specific assumptions, which need not hold for any particular evolutionary process. Therefore IFT is not a general description of natural selection.

In part A of our online material we provide a mathematical analysis to prove this point. If there are non-zero selection intensities, or if there are synergistic interactions, or if there is complex population structure, then it is easy to find situations where the fitness values of individuals cannot be partitioned into additive components as needed by IFT. Essentially, IFT requires fitness to be a linear function of individual actions, but a full understanding of social evolution must take into account the nonlinearity inherent in biological systems.

We distinguish between IFT and standard natural selection theory, because the latter does not require fitness to be split into additive components. We have shown that IFT is a proper subset of the standard theory and makes no independent predictions. Any effect of relatedness is fully captured by the standard approach.

Hamilton's rule states that cooperation can evolve if relatedness exceeds the cost to benefit ratio. If cost and benefit are parameters of individual actions then this rule almost never holds ${ }^{1,3,4}$. There are attempts to make Hamilton's rule work by choosing generalized cost and benefit parameters ${ }^{5}$, but these parameters are no longer properties of individual phenotypes. They depend on the entire system including population structure. These extended versions of Hamilton's rule have no explanatory power for theory or experiment ${ }^{6}$.

Neither IFT nor any formulation of Hamilton's rule can deal with evolutionary dynamics ${ }^{7}$. This fact alone invalidates the claim that IFT "is as general as the genetical theory of natural selection".

Several aspects of our paper are misrepresented in the letters: (i) We do not argue that relatedness is unimportant. Relatedness is an aspect of population structure, which affects evolution ${ }^{8}$. (ii) We do not dispute the importance of kin recognition. Conditional behavior based on kin recognition can be seen as a mechanism for the evolution of cooperation ${ }^{9}$. (iii) Part A of our online material is not a model for evolution of eusociality, but a mathematical framework that demonstrates the limitations of IFT. (iv) Part C of our online material provides a mathematical model 
for the evolution of eusociality, which makes simple and testable predictions and explains the rarity of the phenomenon. (v) Monogamy and sex ratio manipulation may be important for the evolution of eusociality; such ideas are best tested in the context of the explicit model that we propose.

Abbot et al claim that IFT has been tested in a large number of biological contexts, but this is not the case. We do not know of a single study where an exact inclusive fitness calculation was performed for an animal population and where the results of this calculation were empirically evaluated. Fitting data to generalized versions of Hamilton's rule is not a test of IFT, which is not even needed to derive such rules. The limitations of IFT are also demonstrated by its inability to provide useful calculations for microbial evolution ${ }^{10,11}$.

Herre \&Wisclo (H\&W) have presented a one-sided account of cases in halictid eusociality, the details of which do not detract in the least from our argument. Halictid bees were not ignored as stated; we cited them three times. Further, communal halictid bees are "social" only in a primitive sense. They occupy a commons-like tunnel but build and defend their own personal cells as solitary bees $^{12}$. H\&W point out that the experiments of Wcislo ${ }^{13}$ were designed not to allow foraging, tunneling, or guarding, but fail to mention that these behaviors were tested in other experiments ${ }^{14,15}$. Bees are mass provisioners, as H\&W say, and we should have used the phrase "defense and care of young with mass provisioning (bees) or progressive provisioning (others)." We thank H\&W for pointing out this lapsus. Primitively eusocial halictids nevertheless devote considerable care to the cells, guarding them and in many cases opening them to clean out waste.

Various authors mention sex ratio theory, which we do not study in our paper. Nevertheless a precise understanding of sex ratio evolution is based on population genetics and does not require IFT.

There is no support for the claim that evolution maximizes inclusive fitness. Nobody has offered a clear mathematical statement explaining what should be maximized and for which process.

Hamilton's work has stimulated much empirical research and has led to many measurements of relatedness. But we have shown that we cannot rely on IFT to describe how interactions among related individuals affect evolution. IFT is neither useful nor necessary to explain the evolution of eusociality or other phenomena.

It is time for the field of social evolution to move beyond the limitations of IFT. 
1. Nowak, M.A., Tarnita, C.E., Wilson, E.O. The evolution of eusociality, Nature 466, 1057$1062(2010)$

2. Hamilton, W. D. The genetical evolution of social behaviour, I, II. J. Theor. Biol. 7, 1-52 (1964).

3. Cavalli-Sforza L.L., Feldman M.W. Darwinian selection and "altruism". Theor Pop Biol 14, 268-280 (1978).

4. Karlin, S., Matessi, C. Kin selection and altruism. Proc R Soc B 219, 327-353 (1983)

5. Queller, D.C. A general model for kin selection. Evolution 46, 376-380 (1992)

6. Chuang, J.S., Rivoire O., Leibler S. Cooperation and Hamilton's rule in a simple synthetic microbial system. Mol Sys Biol 6, 398 (2010)

7. Traulsen A (2010). Mathematics of kin- and group-selection: Formally equivalent?

Evolution 64, 316-323.

8. Nowak, M.A., Tarnita, C.E., Antal T., Evolutionary dynamics in structured populations. Phil

Trans R Soc B 365: 19-30 (2010)

9. Nowak, M. A. Five rules for the evolution of cooperation. Science 314, 1560-1563 (2006)

10. Diggle, S. P., Griffin, A. S., Campell, G. S. \& West, S. A. Cooperation and

conflict in quorum-sensing bacterial populations. Nature 450, 411-414 (2007).

11. Smith, J., van Dyken, J. D. \& Zee, P. C. A generalization of Hamilton's rule for the evolution of microbial cooperation. Science 328, 1700-1703 (2010).

12. Michener, Charles D. The Social Behavior of the Bees (Cambridge, MA: Harvard University Press, 1974).

13. Wcislo, William T., "Social interactions and behavioral context in a largely solitary bee, Lasioglossum (Dialictus) figueresi (Hymenoptera, Halictidae)," Insectes Sociaux 44, 199-208 (1997).

14. Jeanson, Raphaël, Kukuk, Penelope F. \& Fewell, Jennifer H., "Emergence of division of labour in halictine bees: Contributions of social interactions and behavioural variance," Animal Behaviour 70, 1183-1193 (2005).

15. Shoichi F. Sakagami and Yasuo Maeta, "Sociality, induced and/or natural, in the basically solitary small carpenter bees (Ceratina)," in Yosiaki Itô, Jerram L. Brown, and Jiro Kikkawa, eds., Animal Societies: Theories and Facts (Tokyo: Japan Scientific Societies Press, 1987), pp. 1-16

\section{Box 1: The definition of inclusive fitness given by Hamilton'2.}

"Inclusive fitness may be imagined as the personal fitness which an individual actually expresses in its production of adult offspring as it becomes after it has been first stripped and then augmented in a certain way. It is stripped of all components which can be considered as due to the individual's social environment, leaving the fitness which he would express if not exposed to any of the harms or benefits of that environment. This quantity is then augmented by certain fractions of the quantities of harm and benefit which the individual himself causes to the fitnesses of his neighbors. The fractions in question are simply the coefficients of relationship appropriate to the neighbors whom he affects; unit for clonal individuals, one-half for sibs, one-quarter for half-sibs, one-eighth for cousins,....and finally zero for all neighbors whose relationship can be considered negligibly small." 